\title{
Construction of Indicators of the Self-evaluation Capacity Building through Focused Group for Technical High Schools in Taiwan
}

\author{
Tsai-Feng Cheng, Shi-Jer Lou, Shu-Fen Tseng, and Ru-Chu Shih
}

\begin{abstract}
Evaluation is a beneficial means to maintain and enhance the quality of school management. Currently, the evaluation of technical high schools in Taiwan has been in the third stage. In order to encourage spontaneity and autonomous management of schools, self-evaluation should be actively planned and conducted. Yet, it is lack of appropriate indicators to assess self-evaluation capacity building for technical high schools in Taiwan. The evaluation capacity building (ECB) is a significant trend in the development of evaluation and it can be the important theoretical basis of self-evaluation capacity building for schools. This study aimed to explore the theoretical basis and literature of self-evaluation capacity building (SECB) for schools and to submit the revision of SECB for schools based on ECB; and to construct and amend the first draft of indicators of SECB for schools. To achieve these goals, the indicators of SECB for schools and its revised draft are extracted from literature, and indicators of SECB for schools are constructed through focus group interview with experts and scholars. The major findings of the study reveal that the indicators of SECB for technical high schools can be divided into 3 variables (input, intervening, and outcome variables), 6 categories (individual factor, organizational factor, organizational ability, organizational culture, output, and change), 15 dimensions, and 90 important indicators. Those indicators will be able to assist technical high schools and the administrative units to understand their capacity to build self-evaluation to improve the school performance.
\end{abstract}

Index Terms-Evaluation capacity, school evaluation, self-evaluation capacity building, technical high school.

\section{BACKGROUND}

Evaluation is a beneficial means to maintain and enhance the quality of school management. 12-year Compulsory Education is being carried out in Taiwan, and the quality of school management and the efficacy of schools in technical high schools catch the public's attention. Thus, it's important to efficiently maintain educational quality in technical high school through applying the concept of educational evaluation to school evaluation.

Currently, the evaluation of technical high schools in Taiwan has been in the third stage, so self-evaluation for schools should be actively planned and conducted. Yet, it is lack of appropriate indicators to assess self-evaluation capacity building for schools. Every high school in Taiwan

Manuscript received November 18, 2016; revised April 18, 2017.

Tsai-Feng Cheng and Shu-Fen Tseng are with the National Kaohsiung Normal University, Taiwan (e-mail: t2151@nknu.edu.tw, t1554@nknu.edu.tw).

Shi-Jer Lou and Ru-Chu Shih are with the National Pingtung University of Science and Technology, Taiwan (e-mail: lou@npust.edu.tw, vincent@npust.edu.tw). has taken twice school evaluations. According to the research, self-evaluation can bring schools cultural changes, attract teachers' attention, and increase participation in school affairs, and also it is helpful to development and change of schools [1].

Evaluation capacity building is a significant trend in the development of evaluation and it can be the important theoretical basis of indicators and constructive model of self-evaluation capacity building (SECB) for schools. In the past decade, it has been increasing that evaluation staff use ECB to assist nonprofit organization to develop evaluation skills. It's appropriate to use ECB as the framework to construct indicators of self-evaluation capacity for schools.

Appropriate construction and verification of the indicators and models of SECB for schools can provide references for evaluated schools to continuously develop. Reference [2] shows that inner evaluation is an important process for school to manage autonomously and reflect; thus, it's necessary and prospective to plan assessing indicators of self-evaluation for schools in senior high schools, to make evaluated schools continuously set up self-check plan based on the indicators, and to make school members apply the indicators efficiently, construct complete assessing information for schools to develop clear purposes.

\section{PURPOSE}

The purposes of this study has twofold: one is to explore theoretical basis and literature related to SECB for schools, and to submit the preliminary of revision of SECB for schools based on evaluation capacity building (ECB), and the other is to construct assessing indicators of SECB for technical high schools through focused group.

\section{LITERATURE REVIEW}

Self-evaluation for schools is a cooperative, holistic and reflective process of examination of inner schools. When conduct self-evaluation for schools, principals and teachers in school, parents and students (with legal representatives) are interviewed under the guidance of management committee. The main content of the examination is school affairs. As schools begin self-evaluation for schools, the general goal and outline are clear gradually. Under the concept of schools' context and collective thinking, certain criteria have to be made to accomplish the goals, and appropriate methods have to be adopted to adjudge if schools achieve specified quality. This is an evidence-based examination process, including collection of information 
from everywhere, and the judgement should be focused on learning enhancement of students [3].

According to LaFond and Brown, [4] suggested that to discuss the term "capacity building" only will be vague and confusing because the range which capacity building involves in is too large. And after there is a certain study result in this field, the related concept is developing continuously. The earlier capacity building related researcher thought capacity building is a training process, that is, when there is a gap between actual performance and expected performance in an organization, the general solution is to provide training to or reeducate faltering individuals in an organization, and through the enhancement of capability to strengthen individual's performance. The earlier concept focuses on individual and neglect consistency and holistic of work.

Stockdill, Baizerman, and Compton believed that evaluation capacity building (ECB) refers to the intentional work to continuously create and sustain overall organizational processes that make quality evaluation and its uses routine [5]. ECB can also promote the continuous development of organizational learning and cultivate the perception of enhancing the rate which individuals or groups use results or suggestions of evaluations, that is, ECB can be used to assist to produce expected result [6].

It is found in the literature review that there are 5 theories of evaluation capacity building: evaluation capacity building pathway model (ECBP) [7], evaluation capacity building measure model (ECBM) [8], evaluation capacity building of multidisciplinary model (ECBMP) [9], integrate model of evaluation capacity building (IECB) [10], and the expanded IECB model (EIECB) [10].

The important content of basic evaluation capacity building pathway model (ECBP) and evaluation capacity building measure model (ECBM) are introduced as follows.

The Pathway model was brought by Urban, Burgermaster, Archibald and Byrn (2014) [7]. They suggest though experts and schoalrs keep emphasizing that building evaluation capacity and the quality of evaluation are both important, it is still lack of the tools to identify the high-quality evaluation. Thus, they applied the pathway model and designed the measurement under Systems Evaluation Protocol (SEP), then used it to evaluate the quality of the evaluation plan and the evaluation model. Urban et al. believe the above-mentioned analysis method can integrate paradoxes, that is, when researchers use different methods and produce paradoxical results, the way of integration can be used to find out the differences. The important content of this model is shown below: 1) statement of missions or purposes in the plan: this includes communication of the purpose in the plan, for example, to express the main purpose of the plan; 2) explanation of characteristic in the evaluation plan: for example, statement is a wide-ranging description directed against the plan, not against organization; 3) explanation of execution of the plan: for example, the explanation of the information about target member, the scale of the plan, evaluation process, etc.; 4) explanation of pattern in the plan: for example, the explanation of the information about the pattern of society, culture and equipment in the plan, and all the explanation is the actual situation of the plan; 5) explanation of expected result or goal; and 6) explanation of background of the plan: for example, the explanation of the progress in the development of the plan and/or the reference of proved foundation in related studies. The structure of the pathway model is shown in Fig. 1.

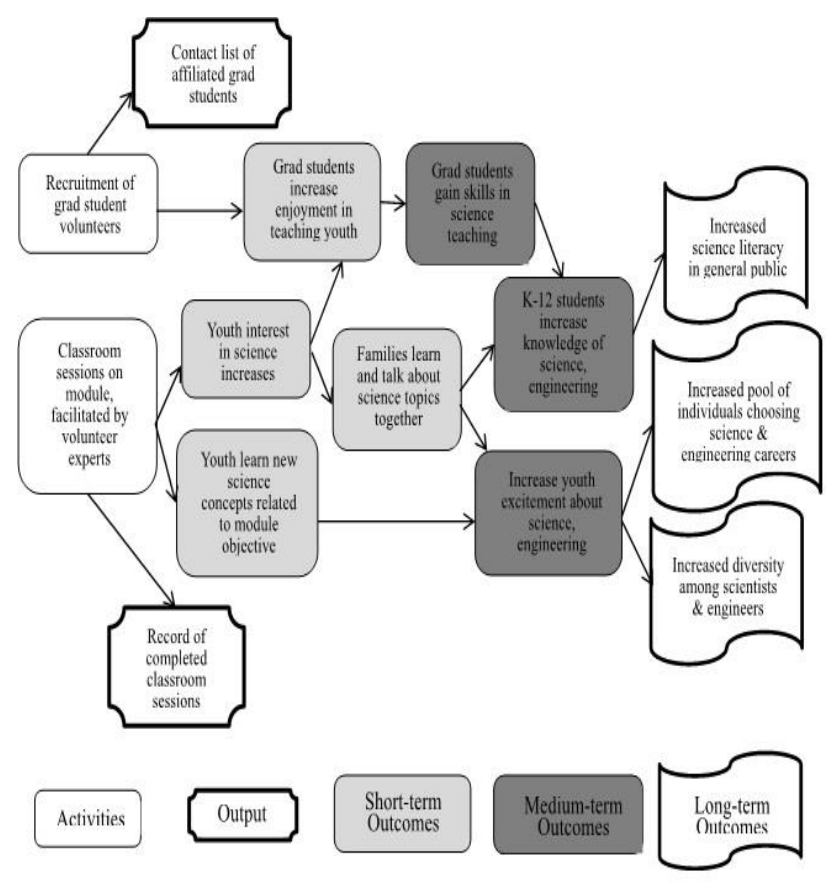

Fig. 1. The structure of the pathway model

Nielsen, Lemirec, and Skov (2011) presented Evaluation Capacity Building Measure Model (ECBM) [8]. Since then, the Evaluation Capacity Building (ECB) has become a practical model, which attracts scholars' attention, for evaluators in evaluation field. Though there are still different concepts of the consistence of ECB in recent related literature review, this leads different capacity dimensions to be attracted and built. In the early literature discussion, a concept of so-called evaluation capacity (EC) was developed. Then researchers used this concept as a foundation to draw the EC structural model and measure tools. They used "evaluation capacity building measure model" to test the public organization in Denmark, and explore the validity in surface, content, and structure of the model based on the empirical evidence. The structure of the evaluation capacity building measure model is as shown in Figure 2.

According to previous studies, the diverse concepts of "evaluation capacity" (EC), Stockdill, Baizerman and Compton (2002) also indicated the efforts to the research in evaluation capacity building are worthy, but there are still many issues like conceptualization, import, evaluation, analysis, and statement needing to be discussed and explored by empirical research.

Besides, from literature review, it is found that there are some common features in every meaning of ECB, for example, everybody thinks that ECB is a process to think outside the box of traditional evaluation. But there are some differences in the meaning at the same time, for instance, some scholars emphasize that ECB is a routine in an organization [5], while some believe that under the exploration of the dimension of individual and organization, no matter individual or organization need to conduct capacity building [9]. Labin, Duffy, Meyers, Wandersman and 
Lesesne suggest that evaluation capacity building (ECB) is a process to enhance personal motive, knowledge, and skills and to strengthen groups or organizations to conduct or use evaluation capability [10].

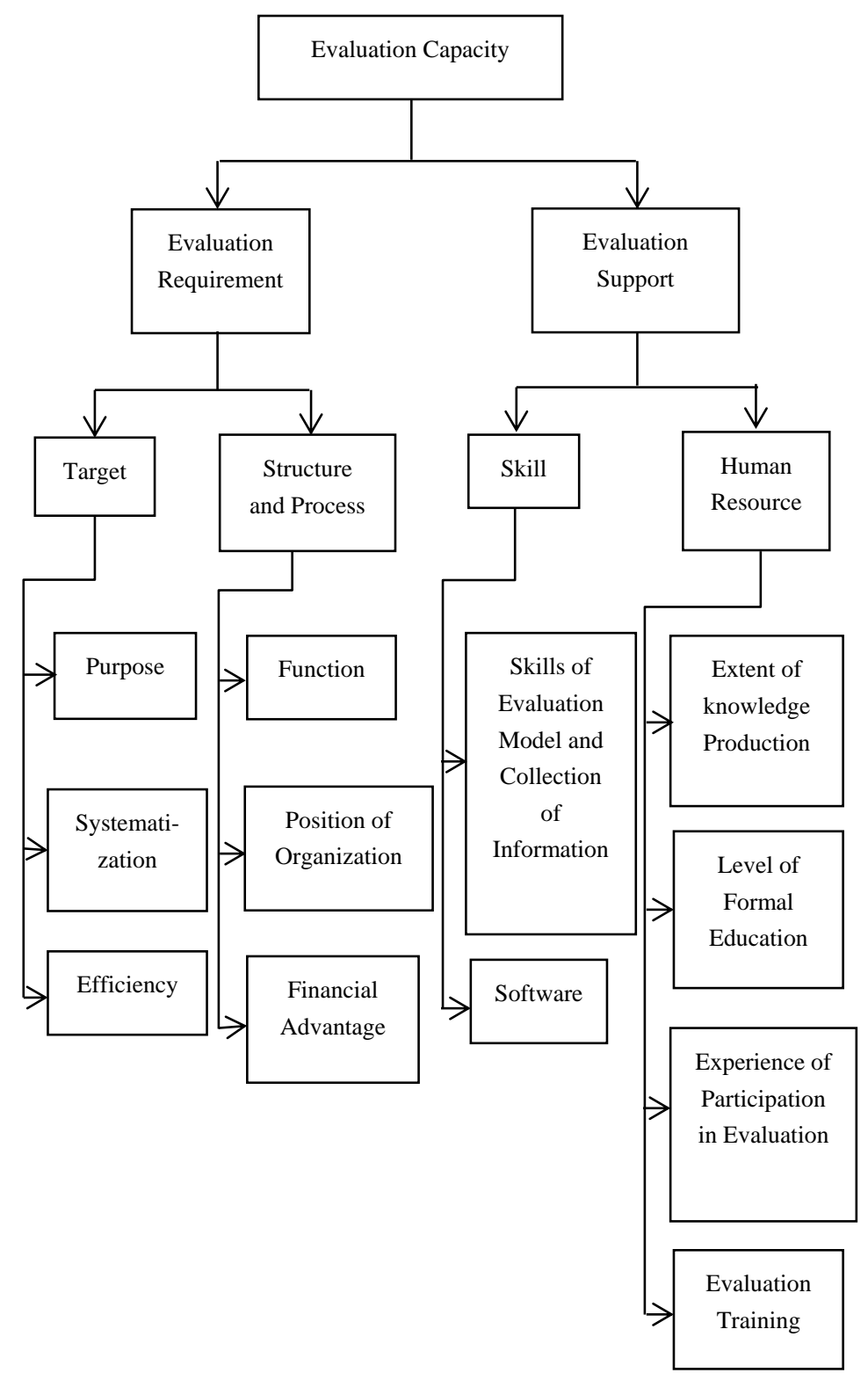

Fig. 2. The structure of the evaluation capacity building measu re model.

After every model above is integrated, revised ECB (RECB) is submitted in this study as show in Figure 3.

From the RECB framework above, SECB for schools can be divided as variable, category, dimension, and indicator. The variables, categories, dimensions, and indicators in SECB for schools are shown in Table 1, and the definition of each dimension is illustrated as follows.

\section{A. Input Variable - The Closest Variable to the Process When Schools Build Self-evaluation Capacity}

Individual Factors include 1) knowledge: the things that participant should understand about ECB; 2) skills: the things that participant should accomplish in ECB; and 3) affection: the things that participant should believe in ECB. The Organizational Factors include 1) leading effectiveness: leaders have specific plans with accomplishable goals, and show leadership with effectiveness; 2) learning environment: the organization can provide members opportunities to evaluate their own business, and encourage them to apply new methods in work processes; and 3) evaluation resource: to provide members skills, time, information, budgets to conduct evaluation activities.

\section{B. Intervening Variable - The Important Factor between Input and Outcome in SECB for Schools.}

The organizational ability includes 1) the ability to improve organizations: to improve the abilities of organizations through encouraging the implement and application of process, policy and practice (PPP); and 2) to apply information efficiently: acceptance, communi- cation and dissemination of information. The organizational culture includes 1) open atmosphere: adaption and expectation of starting the process of evaluation; and 2) organizational learning: peer learning, cooperative learning and to provide opportunities to make decisions.

C. Outcome Variable - Possible Influence and Results Produced After Schools Build Self-evaluation Capacity.

Output includes 1) effectiveness perception: the analysis of attitude perception to SECB for school staff; 2) knowledge 
acquirement: learning related knowledge and its application from the process of SECB; and 3) self-evaluation skills: the assessment of knowledge, skills and behaviors in SECB for school staff. Change includes 1) initiative of evaluation: teamwork, taking risks, making decisions, and peer interaction; and 2) problem solving: improvement, reflection, and assessment of the process of ECB.

TABLE I: THE DRAFT OF BUILDING INDICATORS IN SECB FOR SCHOOLS

\begin{tabular}{lll}
\hline \hline Variable & Category & Dimension \\
\hline \multirow{2}{*}{ Input Variable } & Individual Factor & $\begin{array}{l}\text { knowledge, skills, } \\
\text { affection }\end{array}$ \\
\cline { 2 - 3 } & $\begin{array}{l}\text { Organizational } \\
\text { Factor }\end{array}$ & $\begin{array}{l}\text { leading effectiveness, } \\
\text { learning environment, } \\
\text { evaluation resource }\end{array}$ \\
\hline \multirow{2}{*}{ Intervening Variable } & $\begin{array}{l}\text { Organizational } \\
\text { Ability }\end{array}$ & $\begin{array}{l}\text { ability to improve } \\
\text { organizations, to apply } \\
\text { information efficiently }\end{array}$ \\
\cline { 2 - 3 } & $\begin{array}{l}\text { Organizational } \\
\text { Culture }\end{array}$ & $\begin{array}{l}\text { open atmosphere, } \\
\text { organizational learning }\end{array}$ \\
\hline \multirow{2}{*}{ Outcome Variable } & Outcome & $\begin{array}{l}\text { effectiveness perception, } \\
\text { knowledge acquirement, } \\
\text { self-evaluation skills }\end{array}$ \\
\cline { 2 - 3 } & Change & $\begin{array}{l}\text { initiative of evaluation, } \\
\text { problem solving }\end{array}$ \\
\hline \hline
\end{tabular}

\section{RESEARCH METHOD}

TABLE II: THE NUMBER OF PEOPLE AND TIMES OF FOCUSED GROUP INTERVIEW

\begin{tabular}{lll}
\hline \multicolumn{1}{c}{$\begin{array}{c}\text { Number } \\
\text { of Times }\end{array}$} & $\begin{array}{l}\text { The Number of } \\
\text { People in the First } \\
\text { Focused Group } \\
\text { Interview }\end{array}$ & $\begin{array}{l}\text { The Number of People } \\
\text { in the Second Focused } \\
\text { Group Interview }\end{array}$ \\
$\begin{array}{l}\text { Category } \\
\begin{array}{l}\text { and number of } \\
\text { Scholars and Experts }\end{array}\end{array}$ & \\
\hline $\begin{array}{l}\text { Scholars in Education } \\
\text { Evaluation }\end{array}$ & 3 & 2 \\
\hline $\begin{array}{l}\text { Scholars in Educational } \\
\text { Administration }\end{array}$ & 2 & 1 \\
\hline $\begin{array}{l}\text { Scholars in Technical and } \\
\text { Vocational Education }\end{array}$ & 1 & 10 \\
\hline $\begin{array}{l}\text { Educational } \\
\text { Administrative Staff }\end{array}$ & 1 & 20 \\
\hline $\begin{array}{l}\text { Principals, Directors and } \\
\text { Teachers in Technical } \\
\text { High Schools }\end{array}$ & 3 & 4 \\
\hline $\begin{array}{l}\text { Subtotal } \\
\text { Total }\end{array}$ & \\
\hline \hline
\end{tabular}

To construct the system of indicators of ECB for technical high school, extensive literature and every model of ECB are studied. According to the acquirements from literature, RECB is submitted in this study and the preliminary indicators are deduced based on their connotations. There are 15 dimensions and 90 indicators. Then, 20 scholars and experts in education evaluation field, educational administration field, technical and vocational education field, educational administrative staff, principals and directors in technical high schools are invited. They are divided into 2 groups, 10 persons each time conducting twice focused group interview to acquire the indicators of ECB of technical high school. The indicators are shown as Table II.
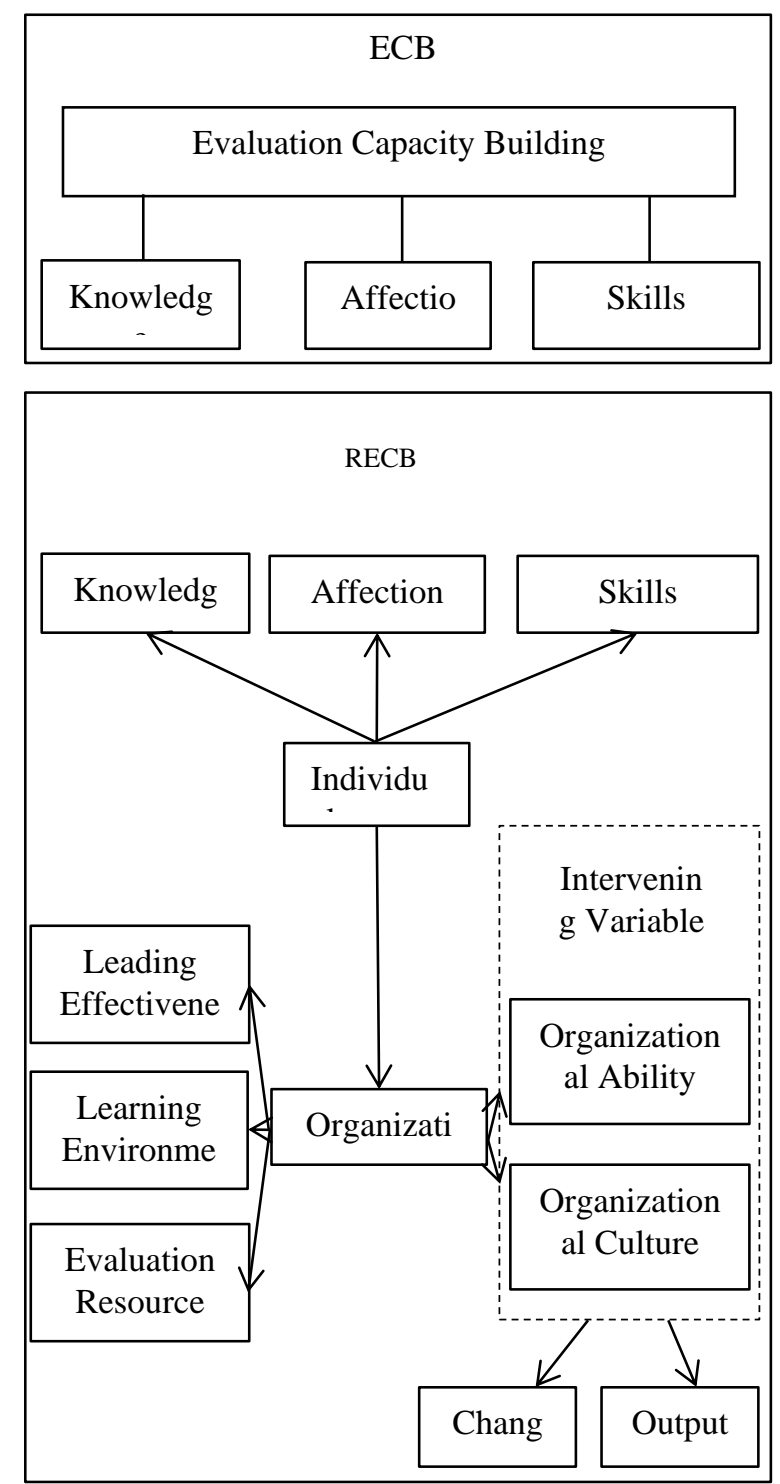

Fig. 3. The framework of revision of the felf-evaluation capacity building (RECB).

The topics discussed by experts and scholars in focus group interview are 1) the variables of SECB for technical high schools are drafted as input variable, intervening variable, and outcome variable. Is there any variable needing to be added or deleted? 2) there are 6 categories of SECB for schools, including individual factor and organizational factor (input variable), organizational ability and organizational culture (intervening variable), and output and change (outcome variable). Is there any category needing to be added or deleted? 3) the categories above are subdivided into 15 dimensions, such as knowledge, skills, affection, leading effectiveness, learning environment, etc. Is there any dimension needing to be added or deleted? 4) making comments on the details of questionnaires, and 5) overall comments. 
The findings of the study are listed as follows:

\section{A. The Appropriateness of Input Variable, Intervening Variable and Outcome Variable in SECB for Technical High School}

Most Interviewees think these three variables are appropriate after discussion between experts and scholars, so input, intervening, and outcome variables are used in this study.

\section{B. The Appropriateness of 6 Categories in SECB for Technical High School}

There are 6 categories in SECB for schools, including individual factor and organizational factor (input variable), organizational ability and organizational culture (intervening variable), and output and change (outcome variable). Most interviewees think these 6 categories are appropriate.

\section{The Appropriateness of 15 Dimensions under Every Category}

6 categories are subdivided into 15 dimensions: knowledge, skills, affection, leading effectiveness, learning environment, evaluation resource, ability to improve the organization, effectively use the information, open atmosphere, organizational learning, effectiveness perception, knowledge acquirement, self-evaluation skills, initiative of evaluation and problem solving. Interviewees also think these dimensions are appropriate because they can accurately correspond to 6 categories.

\section{Making Comments on the Details of Questionnaires of SECB for Technical High School}

According to the opinions of the interviewees in focus group, most of them think indicators are fairly appropriate, but there are still some interviewees have personal opinions on narrative or concept, such as the meaning and the intent of the words or sentences should be more accurate; the subject of the sentences should be clearer, etc. The indicators will be amended based on these opinions.

\section{CONCLUSION}

This study aimed to construct indicators of SECB for technical high schools through literature review and focused group. It is found that indicators can be divided into 3 variables (input, intervening, and outcome variables), 6 categories (individual factor, organizational factor, organizational ability, organizational culture, output, and change, 15 dimensions and 90 important indicators. Those indicators will be able to assist technical high schools and the administrative units to understand their capacity to build self-evaluation to improve the school performance.

Literature review and focus group interview are adopted in this study to construct the indicators. Though the indicators which are acquired have certain reliability and validity, they can be examined through Delphi technique or even extensive investigation of questionnaires. Then these indicators can be used to assess current situation and feasibility of SECB for every technical high school.

\section{REFERENCES}

[1] D. Davies and P. Rudd, Evaluating School Self-evaluation, Slough: NFER, 2001.

[2] D. Nevo, "Dialogue evaluation: Combining internal and external evaluation," in D. Nevo (Ed.) School-Based Evaluation: An International Perspective, Oxford, UK: Elsevier Science, pp. 3-16, 2002.

[3] Inspectorate, Department of Education and Skills. (2012). School self-evaluation guidelines for primary schools. [Online]. Available: http://www.education.ie

[4] A. L. Fond and L. Brown, "A guide to monitoring and evaluation of capacity-building interventions in the health sector in developing countries," MEASURE Evaluation Manual Series, no. 7, Carolina Population Center, University of North Carolina at Chapel Hill, 2003.

[5] S. H. Stockdill, M. Baizerman, and D. W. Compton, "Toward a definition of the ECB process: A conversation with the ECB literature," New Directions for Evaluation, vol. 93, pp. 7-25, 2002.

[6] D. M. Fetterman, S. J. Kaftarian, and A. Wandersman, "Empowerment evaluation: knowledge and tools for self-assessment, evaluation capacity building, and accountability," Thousand Oaks, CA: Sage, 2015 .

[7] J. B. Urban, M. Burgermaster, T. Archibald, and A. Byrne, "Relationships between quantitative measures of evaluation plan and program model quality and a qualitative measure of participant perceptions of an evaluation capacity building approach," Journal of Mixed Methods Research, vol. 201, pp. 1-24, 2014.

[8] S. B. Nielsen, S. Lemire, and M. Skov. (2011). Measuring evaluation capacity: Results and implications of a Danish study. American Journal of Evaluation. [Online]. Available: http://aje.sagepub.com/content/early/2011/01/14/1098214010396075

[9] H. Preskill and S. Boyle, "A multidisciplinary model of evaluation capacity building," American Journal of Evaluation, vol. 29, pp. 443459, 2008

[10] S. Labin, J. Duffy, D. C. Meyers, A. Wandersman, and C. A. Lesesne, "A research synthesis of the evaluation capacity building literature," American Journal of Evaluation, vol. 33, pp. 307-338, 2012.

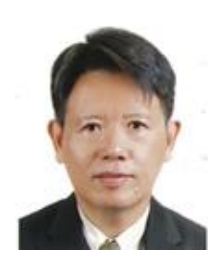

Tsai-Feng Cheng is a full professor in the Department of Education, National Kaohsiung Normal University, Taiwan. His specialties include educational administration, educational evaluation, educational leadership and organizational behavior.

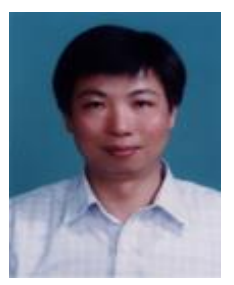

Shi-Jer Lou is a full professor in the Graduate Institute of Vocational and Technological Education, National Pingtung University of Science and Technology, Taiwan. His research interests cover areas in vocational education, teacher education, educational technology, and digital learning.

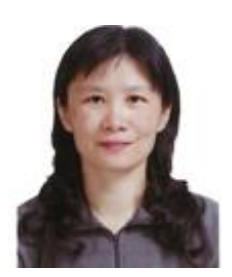

Shu-Fen Tseng is a research assistant in the Department of Education, National Kaohsiung Normal University, Taiwan. She also assists professor Cheng with evaluation affairs.

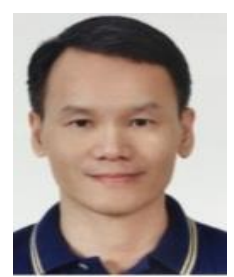

Ru-Chu Shih is a full professor in the Department of Modern Languages, National Pingtung University of Science and Technology, Taiwan. He is specialized in ESL, digital learning, and educational technology. 